\title{
Geo-Environmental Problems of Open Pit Mining: Classification and Solutions
}

\author{
Michaela Koščová ${ }^{1, *}$, Mark Hellmer ${ }^{2}$, Seroni Anyona ${ }^{3}$, and Tatiana Gvozdkova ${ }^{4}$ \\ ${ }^{1}$ Comenius University, Department of Applied Mathematics and Statistics, 84248 Mlynska dolina \\ Bratislava, Slovakia \\ ${ }^{2}$ Imperial College London, SW7 2AZ South Kensington, London, United Kingdom \\ ${ }^{3}$ Jomo Kenyatta University of Agriculture \& Technology, Mining, Materials \& Petroleum \\ Engineering Department, P.O. Box 62000 - 00200, Nairobi, Kenya \\ ${ }^{4}$ Kuzbass State Technical University, Mezhdurechensk branch, 652881, Stroitelei Avenue, 36, \\ Mezhdurechensk, Russia
}

\begin{abstract}
Open mining development is the cheapest method, because it uses powerful production equipment, which allows a large amount of minerals to be excavated during a shift. Working conditions in open development are less dangerous for the health of workers, and a smaller number of supervisory personnel than in underground mining is required. In the process of open development, stripping works are first carried out, i.e. the removal of the empty rocks covering the deposit. Constantly growing requirements for energy sources, metal ores and building materials cause the need for intensive development of the mining industry. There is a rejection of significant areas for the development of minerals in an open and closed way. The causes of degradation are both the mining of minerals, as well as construction, the placement of production and consumption wastes in the natural environment. Changes in the components of the environment are observed as a result of direct or indirect influence of mining enterprises activities. This requires an analysis of the entire complex of geo-environmental problems of open mining and the identification of the most urgent ways to solve them.
\end{abstract}

\section{Introduction}

When developing minerals in the open way, two types of violations can be distinguished: landscape and ecological. Violations of the earth's surface are understood under the landscape violations [1-2]. Under the environmental - the change in living conditions on the lands of the mining allotment and adjacent territories, with a drop in their biological productivity and a sharp decrease in the quality of the environment, which has a depressing effect on flora, fauna and human health [3].

The open mining makes the most negative impact on the hydrosphere. This applies not only to the water spaces in the immediate vicinity of the open pit, but also remote to a distance of several tens of kilometers. The reasons for this negative impact include:

\footnotetext{
* Corresponding author: michaela.koscova@fmph.unibqa.sk
} 
- redistribution of hydrostatic and hydrodynamic pressure of groundwater, their drainage from the upper horizons to the lower ones;

- increasing the water flow from open reservoirs and gutters into open mining;

- filtration of atmospheric precipitation water due to surface disturbance.

The change in the quality of groundwater also occurs due to an additional flow of mineralized water from below or from the side.

Most of the impacts on the atmosphere from open pit mining occur at the development stage (blasting, excavating and moving traffic). However, after the completion of work without the implementation of appropriate remediation works in its area, such phenomena as blowing dust and the emergence of stagnant aerodynamic zones will take place.

\section{Materials and Methods}

Environmental problems of open mining include[4-6]:

1. Air pollution. Mining operations in quarries cause air pollution by gases and solid particles. The spread of the substance through the air and its accumulation near the sources of removal is very intensive. A large amount of dust enters the atmosphere from the enriching factories. Much of its sources are also drilling and blasting operations in quarries, loading and unloading operations and the movement of heavy vehicles on dirt roads, and certain types of ore processing. Air saturation with dust occurs due to the waving of open dumps and other exposed places.

Serious problems are caused by the arrival of heavily dusty air from quarries as a result of explosions, excavation and handling operations. During a shift one 127-ton dump truck pollutes the air to the maximum permissible level of 3.7 million $\mathrm{m}^{3}$. With powerful explosions (up to 500-700 tons of explosives), the mass of explosive rocks is usually 2 million tons, and the volume of the dust and gas cloud is $15-20$ million cubic meters. It is estimated that in the area of Krivoy Rog for 4 hours within a radius of $4 \mathrm{~km}$ from 200 to 500 tons of dust with a particle size of $1.5 \mu \mathrm{m}$ or less spreads to the adjacent land from this cloud. It is also essential that harmful gases emitted during the explosion require 1.7-2.0 $\mathrm{km}^{3}$ of fresh air for dilution to safe concentrations for every $500 \mathrm{~kg}$ of explosives.

About 10 billion cubic meters of rock are annually prepared by explosions in the world. The volume of the total dust and gas cloud reaches $75-100 \mathrm{~km}^{3}$ per year. At the same time, the amount of dust transported can be estimated at 1.0-2.5 million tons.

2. Water depletion as protection of quarries from flooding. The greatest difficulties in mining are due to the inflow of groundwater. Only isolated cases are known, when quarry excavations were completely enclosed by watertight crosspieces-veils. For example, a circular curtain made of artificial waterproof material was created at the Tarnobzek sulfur deposit in Poland.

However, the vast majority of quarries are protected from the inflow of groundwater by pumping. The most significant activities of this kind are held in the basin of the river Rein (the district of Cologne). Here, when working out brown coal strata by the open method, on the average to $1 \mathrm{~km}^{3}$ of groundwater is pumped out annually. Very significant work on dewatering is carried out in the mining of ore minerals. The area covered by water loss in Kursk Magnetic Anomaly (KMA) reached 250 thousand hectares.

The discharge of pumped out and sewage leads to a significant increase in the water content of streams and rivers. The flow of small and medium rivers into the low water increases by 1.5-3 and more times. In particular, in the Kursk region, due to pumped groundwater, especially from un-drained aquifers, the water content of some rivers has increased dramatically. For example, the average annual flow of the river Oskoltsa increased by $21-108 \%$, river Cherni by $20-30 \%$. And this happened despite the fact that both rivers are "hung" in significant areas above the depression funnels of the groundwater 
level and a significant portion of their water (up to 1/5) they lose as a result of infiltration. Artificially increasing water discharge in some rivers leads to an increase in some sections of groundwater levels and flooding of land.

3. Disruptions in the lithosphere. Massive oncoming of the mining industry on the bowels of the Earth causes a wide range of processes on the surface and within the lithosphere. Some of them arise as a direct result of the action of mechanisms, explosions, dissolving substances and microorganisms through which extraction is carried out. The behavior of rocks composing benches, sides and piles on quarries depends on geographic, geological, hydrogeological, engineering-geological and mining conditions. As a rule, landscape changes are observed at the site of worked quarry, geomorphology is broken, hydrological and hydrogeological regimes are changed, and underground horizons are contaminated. The areas in which there are large deposits of crushed stone, dolomite, loam, clay, and native sulfur suffer so much during development of the fields that it is almost impossible to restore the natural landscape in squares of thousands of hectares.

4. Weathering and soil formation. Rocks exposed during the excavations and loaded into dumps in the surface layer undergo intensive weathering.

This process in a temperate climate is carried out with initial velocities of several tens of centimeters per year. However, over time, as the profile of the weathering crust forms, the rate of destruction of rocks gradually decreases.

The surface transformation of the material of the dumps occurs in different ways, depending on their composition and the hydrothermal conditions of the deposit. Dumps, on the surface of which phytotoxic rocks are developed, can for decades serve as an arena of physical and chemical weathering. However, remaining lifeless and bare, they serve as a source of demolition of harmful substances. In the overgrowth of dumps, composed of loose dispersed rocks, a soil profile develops rapidly on them, differing from the zonal profile only by some features.

5. Surface flushing and washing. The walls of excavations and slopes of the dumps are subjected to plane and channelized flow out. The available quantitative assessments of accelerated erosion on these relief surfaces indicate its high intensity. For example, in the Kimovsky and Ushakovsky coal open pits in the Tula region, the washout module from the dumps varies from 1384 to $7959 \mathrm{~m} /$ ha/year, and the average for 10-15 years is 2000-2500 $\mathrm{m} 3$ / ha/year. The resulting removal of $\mathrm{H}+, \mathrm{Be}+2, \mathrm{SO} 4-2$ ions has a negative effect on soil and yield on adjoining croplands. The spread of washout products is significant. The size of the sills is at Ushakovsky open pit from 6.4 to 14.4, and on Kimov - from 8.4 to $31.2 \%$ of the total area of the dumps.

A detailed study of erosion of dump slopes was carried out in Poland, in the Upper Silesian Coal Basin. Dumps are composed of rudaceous rocks with a predominance of crushed stone and rotted rocks. At 10 representative sites, two types of erosion forms were identified: the gullies, cutting through the dumps' slopes all over, and the potholes associated with the edges of the slopes. The growth of flood gully leads to a parallel retreat of the slopes at a rate of $1.73 \mathrm{~cm} /$ year, and the potholes smooth out the bedding portions of the slopes at a rate of $0.5-0.9 \mathrm{~cm} /$ year. With attenuation of erosion, the washing out occurs mainly in the middle part of the slopes $(0.4-0.7 \mathrm{~cm} /$ year). To prevent washing out it is recommended to put the dumps' slopes into a bulged shape without a sharp edge.

On the quarries' dumps in the west of North Dakota (USA), an experimental study of accelerated erosion was carried out. Dumps are formed by loamy overburden rocks. The artificial sprinkling was performed - for two hours the dumps were subjected to $64 \mathrm{~mm}$ of precipitation, and in the case of studying the soil-protective role of straw at a dose of $4.5 \mathrm{t} /$ ha - an additional half-hour sprinkling of the same intensity was carried out. The research was carried out in drainage areas measuring $4 \times 22 \mathrm{~m}$ with inclines from $2{ }^{\circ} 30$ 'to $10^{\circ}$. On overburden rocks covered with a humous layer, the washout reached 74 tons / ha, whereas 
on uncoated rocks its value was 18 tons / ha. Flushing from the pasture area with undisturbed plant cover under the same experimental conditions was only $0.2 \mathrm{t} /$ ha. Thus, when dumps were formed, the surface washout increased by 90-370 times. Straw mulch reduced flushing by $84 \%$ - in areas with a humous layer and $93 \%$ - in areas without this layer. On the basis of the experiment, the scale of amplification was established in the areas occupied by the dumps, and a conclusion was made on the necessity of erosion protection during reclamation.

In the flooded quarries the rate of accumulation is very high. So, on open pits in the Beaver Creek basin, in the state of Kentucky (USA), the bottom sediments in such water bodies varied from tens of centimeters to $1 \mathrm{~m}$. Sedimentation was carried out for 4-6 years.

6. Landslides. This is the most dangerous and widespread form of destruction of slopes and dumps' ledges. In the practice of mining works, landslides with a volume of hundreds of thousands and tens of millions of cubic meters are known. Sometimes landslides in front of the dumps cover areas that are tens of times higher than those occupied by the dumps themselves. Slumping is often preceded by other phenomena, for example, sloughing or the plastic flow of underlying rocks. Often, the slide is accompanied by sloughing. In this case, there are complex landslides - landslides of sloughing, plastic flow, etc.

By the volume of the slipped masses, small landslides (hundreds-thousands of $\mathrm{m}^{3}$ ), medium (tens of thousands of $\mathrm{m}^{3}$ ), large (hundreds of thousands of $\mathrm{m} 3$ ) and very large (millions of $\mathrm{m}^{3}$ ) are distinguished. In addition to landslides, a number of other processes develop in the areas of excavation and deposition of rock masses.

Collapses and landslides are rapid displacements and falls of blocks and packs of rocks that have come off the ledges or sides of the quarry. Cracks often begin with slippage along the cuts of the quarry and the surfaces of weakening.

The movement of rocks in the massif has a different character - from smooth, without disturbing the continuity of rocks, to their complete disintegration. With the depth of the seams being developed less than 30-40 times their thickness, the subsidence of the overlapping rocks is very intensive.

The resulting downwarping can be divided into five types [7-8]:

- synclinal - in the development of deposit seams of medium (from 1.5 to $3 \mathrm{~m}$ ) and large (more than $3 \mathrm{~m}$ ) thickness, horizontal and wavy bedding or dipping at low angles (up to 27 ${ }^{\circ}$ ). Mould of rock dislocation is in the zone of downwarping;

- synclinal terraced - in the development of deposits dipping at low angles or inclined (from $27 \mathrm{O}$ to $45^{\circ}$ ). Mould of rock dislocation is in zones of deflections or collapse;

- canyon - in the development of medium and high thickness seams, dipping at high angles (more than $45^{\circ}$ ), with the falling of the enclosing rocks. Mould shift is in the falling zone; - canyon-like with the remnants - in the development of closely spaced seams with strong host metamorphic rocks, resistant to weathering;

- circular - in the development of steep-dipping stock-like deposits. Mould shift is in the falling zone.

The formation of downwarping is associated with leaching processes and the removal of hydrostatic weighing forces in the zones of depressive funnels. Thus, in Kazakhstan, in the foothills of Karatau, on the outskirts of Kentau in 1978, a karst fault occurred in the Devonian lime-stones. It was accompanied by the earth tremor, a rumble and the formation of a mushroom-shaped column of dust. The mouth area of the downwarping was $1200 \mathrm{~m}^{2}$ and the apparent depth reached $50-55 \mathrm{~m}$. About 30 thousand $\mathrm{m}^{3}$ of gangue was needed to fill the gap. The described phenomenon was caused by the violation of the natural regime of hydrogeological and engineering-geological conditions due to the long-term pumping of water from the existing mine of the poly-metallic plant and the lowering of the groundwater level to a depth of $200 \mathrm{~m}$. A huge depression crater with an area of $1000 \mathrm{~km}$ formed around the deposit covering the whole city. 
Similar phenomena have repeatedly occurred in the area of Johannesburg (South Africa), where underground mining of ore gold is conducted. Here, as a result of the lowering of the groundwater level in the powerful (up to $1000 \mathrm{~m}$ ) Transvaal dolomitelimestone strata, failure holes with a diameter of more than $50 \mathrm{~m}$ and a depth of more than $30 \mathrm{~m}$ and a number of smaller craters repeatedly occurred. In December 1962, suddenly a major downwarping occurred at the plant, located near the trunk of one of the mines. The factory was completely swallowed by downwarping, with the death of 29 people. In August 1964, under similar circumstances, the downwarping swallowed the house together with five residents.

7. Rock bumps and bursting. This kind of exodinamic processes as well as a number of others considered below is carried out through the natural energy sources, whereas human activity serves only as a kind of trigger for them. Rock bumps and bursting occur as a result of instant unloading of elastic deformations of high-strength rocks in places of maximum concentration of stresses and their redistribution in connection with excavations usually at depths of more than $200 \mathrm{~m}$. Sudden outbursts of rocks, water, and gases take place at the intersections of the excavations of tectonic disturbances at depths exceeding $100 \mathrm{~m}$.

8. Underground (endogenous) fires. These natural disasters are the result of spontaneous combustion or burning of coal seams, oil shales or peat bogs in mining operations. Underground fires lead to burnout of significant volumes of combustible rocks and are accompanied by collapse and displacement of geological bodies and significant air pollution.

9. Processes in the cryolithozone. In the field of development of permafrost, man's influence on the earth's crust during the extraction of minerals leads to a very serious disruption of the complexes of natural exodynamic processes. The relative balance in their operation in such areas is based on a very fragile basis, consisting in the approximate constancy of the permafrost conditions of natural soils. In the maintenance of this constancy, the role of vegetative cover and litter, accumulation of which occurs for a long time, is very great.

10. Coal dust and permafrost landscape. The increased amount of coal dust near quarries in the permafrost zone is due to the fact that frozen coals are more fragile, and this causes increased dust formation during their breakdown. The greater separation of coal dust occurs when loading frozen coal in transport on the surface. As a result, the territory around mines and quarries within a radius of $15-20 \mathrm{~km}$ is clogged with coal dust. Melting snow cover occurs here earlier than usual, and the depth of thawing of soils increases by 2.5-3 times compared with the norm. All this causes the formation of lakes and increased swamping of the territory. Because of the dust removal, the water in the lakes in spring period contains up to 30-60 g / 1 of suspended particles and is completely unsuitable for water supply of the population. Pollution of surface water leads to the destruction of zoocenosis on an area much larger than the size of eolian dispersion of coal dust. Such a violation of the natural cycle of substance, in the end, causes a very strong degradation of the landscape.

\section{Results and Discussion}

Priority ways to solve geo-ecological problems caused by the global development of open mining include the following:

The first group of measures is the application of the development system with internal dumping. There were schemes of separation of the quarry field, when initially the part of the quarry is worked out with temporary storage of overburden rocks on the quarry, and the rest is worked on with internal dumping and overburden is sent to the worked-out area. 
The spare area for placement of dumps and tailings of land is reduced by implementing the following measures:

- placement of dumps on unfit and poorly agricultural land;

- the use of waste rock and the soil layer removed during industrial construction for improving the adjacent areas (ravines, ravines, inadequate lands);

- the improvement of dumping process itself (choice of the method of dumping with the least estrangement of lands or with the possibility of implementing a quick and simple reclamation scheme);

- timely reclamation of dumps.

The second group of measures relates to the fight against the pollution of the atmosphere of quarries with dust and aerosols:

- suppression, binding and trapping of dust during drilling and blasting operations ("wet" drilling, drilling with dust extraction, the use of explosions without the collapse of the rock mass, irrigation with water and solutions, the use of foams, etc.);

- application of emulsion and film coatings to dumps, sides of quarries and also their irrigation;

- biological reclamation of dumps and quarry excavations;

- disposal of waste rock.

The third direction - improving the state of water resources is aimed at reducing the impact of mining and quarry water on them. There are preventive and radical measures.

Preventive measures include:

1. Reduction of water inflows into the mine workings through the organization of predrainage, barrier drainage (including contour and with the use of water-absorbing well systems that ensure minimal change in water bodies of adjacent territories), absorbing drainage with isolated drainage of water, isolation of water sources, for example, waterproof curtains (screens), reliable systems of canalization of storm and thawed runoff from the territory of the mining allotment, pumping out the accumulations of thawed and raining water from the settling zone and falling surface, the processing water flow in accordance with the rules;

2. Direction of water inflows along the paths providing minimum associated additional pollution (including a device isolated from the rock massif of the drainage ditches), in quarries - regulation of the internal water flow with the arrangement of temporary sedimentation ponds.

The radical measures include: purification of mine waters (neutralization, clarification from mechanical impurities, extraction of organic compounds, salts and metals by chemical, physical and biological methods); use of mine waters in a closed cycle of mining and ore-processing industries.

In addition, work is carried out to neutralize wastewater from the territory of the mining enterprise. This includes the treatment of waste water from oils and other organic substances, as well as from mechanical impurities, cooling to the norm and a number of other measures.

\section{Conclusion}

The extraction of minerals affects relatively small areas. However, due to the huge energy contribution to these activities by a man, from mining areas so many substances are transferred during a small period of time than only volcanic apparatuses can move and disperse more in large eruptions on the Earth. The manifestation of natural-anthropogenic processes in mining territories is mainly due to: 1) disturbance of the stress state of the earth's crust, 2) the ability of organogenic rocks to spontaneous and prolonged combustion, 
3) change in hydrogeological and hydrological conditions, 4) a large amount of water 5) dissipating heat, 6) unprecedented in intensity destruction of the soil-vegetation layer.

Therefore, when carrying out mining operations, linear construction and other activities that sharply worsen the state of the landscape, a complex of remediation transformations is also envisaged in advance. At the same time, when planning the production of the main type of work, for example, mining, it is envisaged to create optimal conditions for reclamation. Such advanced planning of reclamation has a great future and opens wide prospects to the branches of science and technology related to the problems of rational nature management.

\section{References}

1. O. Litvin, M. Tyulenev, S. Zhironkin, S. Prokopenko, Methodology of coal losses calculation at open pit mining for complex geological conditions - review, Acta Montanistica Slovaca, 22:2, 146-152 (2017)

2. T. Gvozdkova, M. Tyulenev, S. Zhironkin, V. A. Trifonov, Yu. M. Osipov, Rational Use of Land Resource during the Implementation of Transportless System of Coal Strata Surface Mining, IOP Conference Series: Earth and Environmental Science, 50:1, 012010 (2017)

3. M. Tyulenev, Y. Lesin, E. Tyuleneva, E. Murko, The Experience of Using Innovative Artificial Filter Arrays on South Kuzbass Open Pit: Case Study, E3S Web of Conferences, 15, 02003 (2017)

4. M. Tyulenev, S. Zhironkin, E. Tyuleneva, A. Abay, S. Anyona, M. Hellmer, The calculation of coal losses in open pit faulted areas, Coal International, 265:3, 30-34 (2017)

5. M. Tyulenev, Y. Lesin, O. Litvin, E. Maliukhina, A. Abay, Increasing the Reliability of the Work of Artificial Filtering Arrays for the Purification of Quarry Waste Water, E3S Web of Conferences, 21, 02019 (2017)

6. S. Markov, M. Tyulenev, O. Litvin, E. Tyuleneva, Innovative numerical modelling of technogenic rock arrays structure, E3S Web of Conferences, 15, 01011 (2017)

7. V.A. Gogolin, Yu.A. Ryzhkov, Elastic interaction of wall rocks with stowing material and the coal seam, Soviet Mining Science, 17(2), 156-159 (1981

8. S. Markov, V. Martyanov, E. Preis, A. Abay, Technogenic Rock Dumps Physical Properties' Prognosis via Results of the Structure Numerical Modeling, E3S Web of Conferences 21, 01021 (2017) 